\title{
CLINICOPATHOLOGICAL CORRELATION OF OVARIAN TUMORS IN DARBHANGA MEDICAL COLLEGE AND HOSPITAL, LAHERIASARAI, BIHAR
}

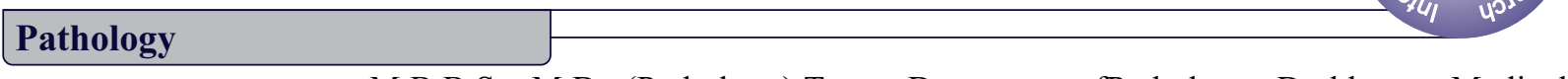

Dr. Megha Jha

M.B.B.S., M.D. (Pathology),Tutor, DepartmentofPathology, Darbhanga Medical College, Laheriasarai, Bihar.

Dr. Hari Shankar M.B.B.S., M.D. (Pathology), Associate Professor, Department of Pathology, Darbhanga Mishra*

Dr. [Prof.] Ajit Kumar Chaudhary

Dr. Debarshi Jana

Medical College, Laheriasarai, Bihar. ${ }^{*}$ Corresponding Author

M.B.B.S., M.D. (Pathology), Professor and Head of Department,Department of

Pathology, Darbhanga Medical College, Laheriasarai, Bihar.

Young Scientist (DST) Institute of Post-Graduate Medical Education and Research,

A.J.C. Bose Road, Kolkata-700020, West Bengal, India

\section{ABSTRACT}

Introduction and Objective: Ovary is one of the complex organs in terms of its embryology, histology, steroidogenesis and tumor incidence. The present study highlights the correlation between the clinical and pathological features of neoplastic lesions of ovary in order to arrive at a better understanding of the disease process. The objective of study is to assess the overall incidence of various histological types of ovarian neoplasm, the pattern of occurrence of ovarian tumors in relation to age, parity and modes of presentations and to study the histopathological findings of various ovarian tumors. Materials and Methods: Biopsies received at the Department of Pathology, Darbhanga Medical College and Hospital, Laheriasarai, Biharwere subjected for histopathological study. Specimens were then fixed in $10 \%$ formalin for $24-48$ hour, processed and embedded in paraffin blocks. Sections of 4-6 microns thickness were taken and stained with routine haematoxylin and eosin and studied. IHC was done whenever necessary. Result: Out of 92 cases of ovarian tumors 68 cases were benign, 3 were borderline and 21 were malignant. Serous cystadenoma formed the majority (38\%) among benign lesions and among malignant lesions serous cystadenocarcinoma (5.4\%) were common. Majority were surface epithelial tumors and constituted $64.13 \%$ (59 cases) with germ cell tumors $26 \%$ ( 24 cases) and sex cord stromal tumors $8.6 \%$ ( 8 cases). Conclusion: The correct histopathological diagnosis of ovarian tumor is of prime importance in view of their behavioural predictability, clinical correlation and the proper management of patient.

\section{KEYWORDS}

Ovary, Tumor, Histopathology.

\section{Introduction}

An adnexal mass (mass of the ovary, fallopian tube, or surrounding connective tissues) is a common gynaecologic problem. In the United States, it is estimated that there is a 5 to 10 percent lifetime risk for women undergoing surgery for a suspected ovarian neoplasm.1Ovarian cancer is the leading cancer in women (affecting about $1 / 70$ ) and leading cause of death from gynaecological cancer. It is the 5th leading cause of cancer fatalities in women2 after lung cancer, breast cancer, colon cancers and cervical cancer. Ovarian neoplasms remain asymptomatic until massive ovarian enlargement cause compression of pelvic structures, ascites, abdominal distension and distal metastasis. The ovary not only gives rise to a wide variety of malignancies but is also a favourite site for metastases from many other organs.

Ovarian neoplasms are notorious for wide range of histologic differentiation that can be found in different areas of the same neoplasm. The present study is undertaken to analyse the ovarian tumours and their characteristics with regard to age, parity and mode of presentation, further a detailed study of various histological types of ovarian tumours is also done.

\section{Materials and Methods}

92 cases of ovarian tumours received in the Department of Pathology, Darbhanga Medical College and Hospital, Laheriasarai, Bihar were studied. The study was undertaken during the period October 2019 to September 2020.The materials were received as surgically resected specimen from patients operated in the hospital. Clinical details like age, obstetric history, menstrual irregularities and other constitutional symptoms were collected in the proforma. CA 125 level was measured for 20 patients who were clinically and sonologically suspected to have ovarian tumour. On receiving the specimen, gross features such as size, shape, colour, external appearance, findings on cut section and contents were noted. Then the tumours were cut at various levels depending on the individual cases and they were allowed to fix in $10 \%$ formalin for 24-48 hours. After formalin fixation, multiple bits were taken from representative areas of tumours and the accompanying tissues. They were processed for histopathological examination and paraffin blocks were made. The blocks were cut at 3-5 microns thickness and stained with Haematoxylin and Eosin. Detailed microscopic examination of the tumour was done to arrive at a histopathological diagnosis following the WHO classification of the ovarian tumours

For a case of Granulosa cell tumour IHC with Inhibin was done. (Fig. 6) The data compiled was analysed for various parameters like age, parity, oral contraceptive use, clinical signs and symptoms, gross features of the tumours and the incidence of the different histological types.

\section{Results}

Ninety-two cases of ovarian tumours received in the Department of Pathology, DMCH, Laheriasarai, Bihar during the period of 1 year from October 2019 - September 2020 were studied. Out of 92 cases of ovarian tumours, 68 were benign, 3 were tumours of low malignant potential and 21 were malignant. (Table 1 ).

Table 1 : Distribution of ovarian tumours

\begin{tabular}{|c|c|c|}
\hline Type of tumour & No. of cases & Percentage \\
\hline Benign tumour & 68 & $73.9 \%$ \\
\hline Borderline tumour & 3 & $3.2 \%$ \\
\hline Malignant tumour & 21 & $22 \%$ \\
\hline Total & 92 & $100 \%$ \\
\hline
\end{tabular}

The surface epithelial tumours were the commonest tumours accounting for $64.13 \%$, germ cell tumours were $26 \%$ of cases and sex cord stromal tumours formed $8.6 \%$ and metastatic tumour $1 \%$ In the present study, the youngest patient was 14 months and the oldest was 75 years forming a range of 14 months to 75 years. Highest incidence of ovarian tumour was noted in the third decade i.e. 28 cases out of 92 cases accounting for $30.43 \%$. Highest incidence of benign ovarian tumour was noted in third decade i.e. 25 cases out of 68 accounting for $36.76 \%$. Highest incidence of malignant tumour was noted in the fourth decade i.e. 10 out of 21 cases accounting for $47.61 \%$ (Table 2).

Table 2 :Age group distribution of benign, borderline and malignant ovarian tumours

\begin{tabular}{|c|c|c|c|c|c|}
\hline $\begin{array}{c}\text { Age in } \\
\text { yrs. }\end{array}$ & Benign & Borderline & Malignant & Total & Percentage \\
\hline
\end{tabular}




\begin{tabular}{|c|c|c|c|c|c|}
\hline $0-10$ & 2 & - & 2 & 4 & $4.3 \%$ \\
\hline $11-20$ & 2 & - & - & 2 & $2.1 \%$ \\
\hline $21-30$ & 12 & - & 1 & 13 & $14.1 \%$ \\
\hline $31-40$ & 25 & - & 3 & 28 & $30.4 \%$ \\
\hline $41-50$ & 18 & 3 & 10 & 31 & $33.6 \%$ \\
\hline $51-60$ & 4 & - & 3 & 7 & $7.6 \%$ \\
\hline $61-70$ & 5 & - & - & 6 & $6.5 \%$ \\
\hline $71-80$ & - & - & 2 & 2 & $2.17 \%$ \\
\hline Total & 68 & 3 & 21 & 92 & $100 \%$ \\
\hline
\end{tabular}

Presenting Complaints: The distribution of symptoms is varied. $35 \%$ of the patients complained of dull aching lower abdominal pain, $27 \%$ complained of abdominal mass and $6 \%$ of the patients gave history of menstrual disturbance like menorrhagia. History of postmenopausal bleeding was given by 4 patients with benign tumours. (Table 3 ).

\section{Table 3 :Symptoms of ovarian tumours}

\begin{tabular}{|c|c|c|c|c|}
\hline $\begin{array}{c}\text { Clinical } \\
\text { presentation }\end{array}$ & $\begin{array}{c}\text { No. of cases } \\
\text { Benign } \\
\text { Tumour }\end{array}$ & $\begin{array}{c}\text { No. of cases } \\
\text { Borderline } \\
\text { Tumour }\end{array}$ & $\begin{array}{c}\text { No. of cases } \\
\text { Malignant } \\
\text { Tumour }\end{array}$ & Percentage \\
\hline Pain abdomen & 27 & 2 & 4 & $35.86 \%$ \\
\hline $\begin{array}{c}\text { Mass per } \\
\text { abdomen }\end{array}$ & 20 & 1 & 4 & $27.13 \%$ \\
\hline $\begin{array}{c}\text { Pain abdomen } \\
\text { with mass }\end{array}$ & 7 & - & 4 & $11.95 \%$ \\
\hline $\begin{array}{c}\text { Menstrual } \\
\text { disturbance }\end{array}$ & 4 & - & 2 & $6.52 \%$ \\
\hline $\begin{array}{c}\text { Urinary } \\
\text { disturbance }\end{array}$ & 2 & - & 4 & $6.52 \%$ \\
\hline $\begin{array}{c}\text { Constitutional } \\
\text { symptoms }\end{array}$ & 4 & - & 2 & $6.52 \%$ \\
\hline $\begin{array}{c}\text { White } \\
\text { discharge per } \\
\text { vagina }\end{array}$ & 4 & - & 1 & $5.43 \%$ \\
\hline
\end{tabular}

Physical signs: $27 \%$ of the patients had a pelvic mass. $12 \%$ of patients complained of dull aching lower abdominal pain and tenderness. Ascites was seen in 2 patients with mucinous cystadenocarcinoma and 2 patient in serous cystadenocarcinoma.

Parity: 6 patients were not married and all were below twenty years of age. Among married, 81 were parous and remaining were nulliparous. (Table 4)

Table 4 :Distribution of ovarian tumours in parous women

\begin{tabular}{|c|c|c|c|}
\hline \multirow{2}{*}{$\begin{array}{c}\text { Types of } \\
\text { tumours }\end{array}$} & \multirow{2}{*}{ Unmarried } & \multicolumn{2}{|c|}{ Married } \\
\cline { 3 - 4 } & & Nulliparous & Parous \\
\hline Benign & 4 & 5 & 59 \\
\hline LMP & 0 & 0 & 3 \\
\hline Malignant & 2 & 0 & 19 \\
\hline Total & 6 & 5 & 81 \\
\hline
\end{tabular}

Associated Conditions: Out of 92 cases of ovarian tumors, 22 were associated with appendicitis and 12 were associated with uterovaginal prolapse. (Table 5)

Table 5 : Conditions associated with ovarian tumours

\begin{tabular}{|c|c|c|}
\hline Sl. No. & Associated conditions & No. of cases \\
\hline 1 & Utero Vaginal prolapse & 12 \\
\hline 2 & Leiomyoma & 5 \\
\hline 5 & Appendicitis & 22 \\
\hline 6 & Calculus cholecystitis & 1 \\
\hline 7. & Pregnancy & 1 \\
\hline
\end{tabular}

Oral Contraceptive use: None of the above 92 patients gave history of OCP use.

Family History: This may not be significant as the patients were not aware of the cause of death of their relatives.

The tumours were classified according to the WHO histological classification of the ovarian tumours and the incidence of different histological types noted. (Table 6).

Table 6 :Incidence of various histological types of the ovarian tumours

\begin{tabular}{|l|c|c|}
\hline \multicolumn{1}{|c|}{ Types of Tumour } & No. of cases & Percentage \\
\hline I. Common Epithelial Tumours & & \\
\hline A. Serous tumours & 59 & $64.13 \%$ \\
\hline a) Benign & 35 & $38 \%$ \\
\hline b) Low Borderline malignancy & 2 & $2.17 \%$ \\
\hline c) Malignant & 5 & $5.4 \%$ \\
\hline B. Mucinous tumours & & \\
\hline a) Benign & 7 & $7.6 \%$ \\
\hline b) LBM & 1 & $1 \%$ \\
\hline c) Malignant & 4 & $4.3 \%$ \\
\hline C. Mixed epithelial tumours Benign & & \\
\hline Malignant & 1 & $1 \%$ \\
\hline D. Endometrioid carcinoma & 4 & $4.3 \%$ \\
\hline E. Transitional cell carcinoma & - & \\
\hline F. Undifferentiated carcinoma & & \\
\hline II. Sexcord stromal tumours & 08 & $8.6 \%$ \\
\hline A. Granulosa cell tumour & 3 & $2.17 \%$ \\
\hline B. Fibroma/thecoma & 5 & $5.4 \%$ \\
\hline III. Germ cell tumours & 24 & $26 \%$ \\
\hline A. Dysgerminoma & 1 & $1 \%$ \\
\hline B. Endodermal Sinus tumour & 1 & $1 \%$ \\
\hline C. Embryonal carcinoma & - & \\
\hline D. Teratoma, mature cystic & 21 & $22.8 \%$ \\
\hline E. Immature teratoma & 1 & $1 \%$ \\
\hline IV. Metastatic tumours & & \\
\hline Krukenbergtumour & 1 & $1 \%$ \\
\hline
\end{tabular}

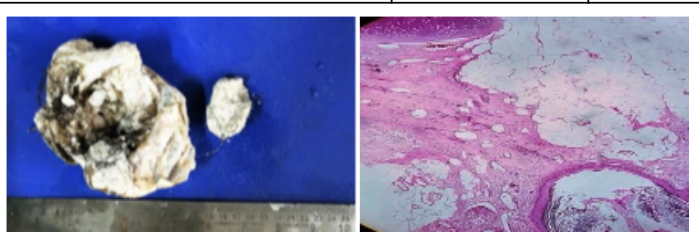

Fig. 1: Hair shaft and greasy material in mature cystic teratoma Fig. 2: Benign cystic teratoma- 10x showing keratin, sebaceous glands and cartilage

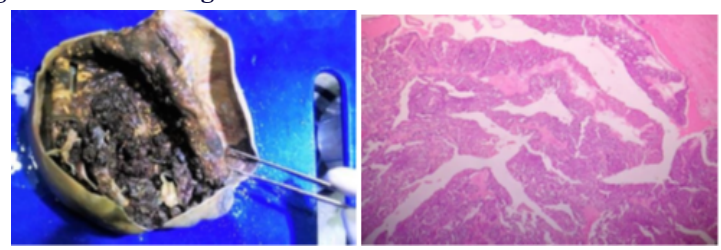

Fig. 3: Papillary excrescences in the cystic cavity

Fig. 4: Papillary serous cystadeno carcinoma

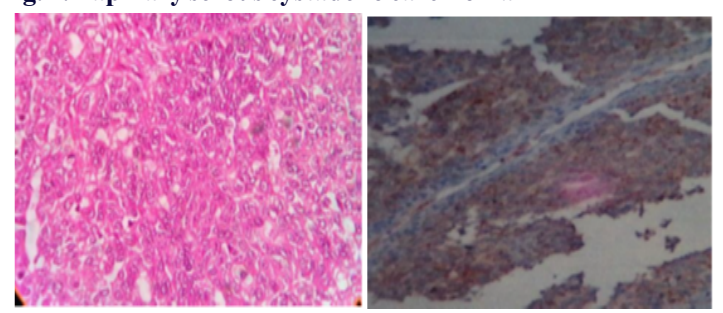

Fig. 5: Granulosa cell tumor - 10x shows cuboidal to polygonal cells having coffee bean nuclei with folds

Fig. 6: Inhibin positivity

\section{CHARACTERISTICS OFTHE TUMOURS:}

Site of Involvement: Left sided tumours of ovary (51.08\%) were more common than right sided tumours(43.47\%). 5 cases were bilateral out of which 2 were borderline and 3 malignant.

Size of the Tumours: The largest tumour (mucinous cystadenoma) in the present study measure $34 \times 26 \times 28 \mathrm{~cm}$ in size and weighed $11 \mathrm{~kg}$ while the smallest tumour (serous cystadenoma) was $2 \times 2 \times 1 \mathrm{~cm}$ in size and weighed 50gms. (Fig. 3)

CA 125 level was measured for 20 patients who were clinically and ultrasonographical suspected to have ovarian tumours. Of that, only 12 
patients had elevated levels $(>35 \mathrm{U} / \mathrm{ml})$. Also in that group of 12, it was noted that Ca125 level was above $35 \mathrm{u} / \mathrm{ml}$ but not beyond $100 \mathrm{u} / \mathrm{ml}$ in benign tumours. The mucinous carcinomas showed moderately elevated levels of $105 \mathrm{u} / \mathrm{ml}$ and $360 \mathrm{u} / \mathrm{ml}$. relatively much elevated levels were noted in serous carcinoma and malignant mixed mulleriantumour, $678 \mathrm{u} / \mathrm{ml}$ and $575 \mathrm{u} / \mathrm{ml}$ respectively.

\section{Discussion}

Ovarian/tubal neoplasms may arise from stem cells, which typically give rise to the surface epithelium, fallopian tube epithelium, germs cells, or sex cord-stromal cells. The incidence, clinical appearance and the behaviour of the different types of ovarian tumours is extremely variable. Through physical examination, imaging studies like pelvic ultrasound and laboratory studies like serum biomarkers and immunological tests have been reported to be of some help in predicting the nature of the pathology. It is generally impossible to diagnose the nature of the ovarian tumours preoperatively. Surgical evaluation allows a definitive histologic diagnosis. Microscopic examination and diagnosis is essential for further management of the tumour.

Out of 92 ovarian tumours in the present study $73.9 \%$ were benign tumour, $3.2 \%$ were borderline tumours and $22 \%$ were malignant tumours.

Nature of the Tumors: Among the different histopathological patterns the surface epithelial tumours formed the largest group of tumour ( 59 cases, $64.13 \%$ ) followed by the germ cell tumour ( 24 cases, $26 \%$ ), sex cord stromal tumours of ( 8 cases, $8.6 \%$ ) and metastatic tumours $(1 \%)$.

Nalini et al in 2007 and Mondal et al ${ }^{5}$ in 2011 observed that the epithelial tumours were the most frequent tumour followed by germ cell tumours and sex cord tumours.

The commonest epithelial tumours were serous cystadenoma (35 cases) and the commonest germ cell tumour was benign cystic teratoma (21 cases) in the present series. Similar observations were made by Mondal SK et al in 2011 and Nalini et al in 2007.

Among the benign lesions, serous cystadenoma was the commonest (35 cases, 38\%) (Fig. 3) followed by mature cystic teratoma (21 cases, $22.8 \%$ ) (Fig. 1, Fig. 2) in the present study. This was similar to the observations of Di Bonito et al, Nalini et al and Mondak SK et al. But Ahmed et al, in his paper, stated that mature cystic teratoma (35.17\%) was the commonest benign tumours followed by surface epithelial tumours. The commonest malignant tumours in the present study is serous cystadenocarcinoma (5.4\%) (Fig. 4) and the next commonest being Mucinous cystadenocarcinoma and endometrioid carcinoma each constituting $4.3 \%$, this is followed by Granulosa cell tumour 3.2 $\%$ (Fig. 5) and Metastatic tumour 1\%. In a study from eastern India, the same was found to be $5 \%$ of all malignant tumors.

Laterality: 5 cases $(5.43 \%)$ of bilateral ovarian tumour were seen in the present study, of which 3 cases were malignant serous cystadenocarcinoma. similar findings have been reported by Couta F et al whereas Ramachandran G et al, Gupta SC et al and Kapas MM et al reported more number of bilateral tumours compared to the present study.

Bilaterality in malignancies implies spread to the opposite ovary as part of extension throughout the pelvis and abdomen as seen in advanced cases.

Site of Involvement: In the present study, there were $51.08 \%$ of left sided tumours and $43.47 \%$ of right sided tumours, the remaining $5.4 \%$ were bilateral.

Ramachandran $\mathrm{G}$ at el found $46.04 \%$ of all ovarian tumours on the right side and $38.5 \%$ on the left side. The rest were bilateral.

Age: The youngest age is a 14 months old child with mature cystic teratoma. Similarly Pilli et al reported the youngest patient of 8 months. In the present study majority of benign tumours occurred in the 31-40 years of age group and the carcinomas were more common at 41-50 years of age group. Surface epithelial tumours varied widely involving all age groups. The present findings concurred with those of
Ashley DJB(1990) and Herbst A (1994). Similar observations were also made by Ramachandran G et al and Mondal SK et al in 2011.

Parity: In 2006 Gunnar et al did a prospective study onreproductive factors and risk of ovarian cancer in 6565 females in Norway and found that highest risk of ovarian tumours was observed among nulliparous women. The risk decreased significantly with increasing parity.

In 2006 Marine et al did a study on the incidence of ovarian cancer on 87,929 grand multiparous women and concluded that the risk of ovarian cancer was low in all grand multiparous women, no matter how many children and at which age they delivered or contracted cancer.

Out of 92 cases in the present study, 81 were multiparous, 11 were nulliparous of whom 6 were unmarried

Oral Contraceptive Pills Use: In a review of epidemiological study of ovarian carcinoma, Herbst al stated that nulliparous and infertile women particularly those who had used fertility drugs, had an increased risk of ovarian carcinoma. Surprisingly no patients gave the history of any oral contraceptive use in the present study. This might be because of the fact that majority of the patients had come from a rural background.

Family History: Very few patients in present study gave family history of ovarian and breast cancer majority of the patients were ignorant of the exact cause of the death of their parents, siblings and other relatives.

However, Gershenson DM stated that familial ovarian cancer probably accounts for no more than $3 \%$ of all epithelial ovarian cancers, with the sporadic form comprising the vast majority of cases. According to Anderson MC, $5 \%$ of women who get ovarian cancer have no family history of the disease.

Symptoms: The commonest clinical features in the present study were pain in the lower abdomen $(35.86 \%)$ followed by mass per abdomen $(27.17 \%)$.

Present study concorded with Pilli et al13 where abdominal pain was the commonest symptoms. But cases presenting as mass per abdomen were less in the present study when compared to other studies.

Size of the Tumors: The largest tumours encountered in the present study was mucinous cystadenoma measuring $35 \times 28 \times 26 \mathrm{cms}$ in size. Similar observations were made in Tyagi et al and Gupta et al who reported a mucinous cystadenoma with maximum diameter of $44.5 \mathrm{cms}$. Majority of the cases were uni/multilocular with a cystic appearance. The tumours with mixed solid and cystic areas and completely solid tumours were mostly malignancies. Similar observations were made by Gupta SC et al11 and Maheshwari et al.

Serum CA 125 Level: Serum CA 125 is the most commonly used laboratory test for the evaluation of adnexal masses for Epithelial Ovarian Carcinomas. CA 125 is a high molecular weight glycoprotein which is widely used prospectively to evaluate the therapeutic efficacy and to monitor the disease status among ovarian cancer patients. The sensitivity of serum CA125 level for stage I disease is lower (50\%) than for stage II $(90 \%)$ or higher disease. The prevalence of an elevated serum CA125 is highest in women with serous histology and lower in those with mucinous tumours, many of which are associated with normal level of CA125.In premenopausal women, elevated serum CA 125 levels are nonspecific and may be elevated due to nongynaecological reasons and benign abdominal disorders like pregnancy, PID, endometriosis, uterine fibroid, spontaneous abortions etc. In contrast, an elevation of serum CA 125 level in postmenopausal women indicates the necessity for prompt surgical exploration as it is most likely associated with ovarian carcinoma.

\section{References}

1. Ahmed Z, Kalyani N, Hassan SH, MuzaffarS, Gilli MS Histological pattern of ovarian neoplasm. J Pakistan medical association 2000:50:46-49

2. American College of Obstetricians and Gynecologists committee on Gynecologicpractice. Committee opinion no.477: the role of obstetrician-gynecologis in the early detection of epithelial ovarian cancer. Obstetgynecol 2011;117;742.

3. Anderson MC: Female Genital tract, systemicpathology, vol 6, symmers W, st.c,3 Edition 1991, Churchil, livingstone.

4. Basu P, DeP, Mandal S, Ray K, Biswan J, study of patterns of Ovarian cancer patients in a 
specialized Ca institute n Kolkata, Eastern India Use the "Insert Citation" button to add citations to this document. Indian J Cancer 2009;46:28-23.

5. Batcharya MM, Shinde SD, Purrandare VN. A clinicopathological analysis of 270 ovarian Tumors J. Postgradmed, 1980:26;103-7.

6. Carlson KJ, SkatesSJ, Singer DE. Screening for Ovarian cancer. Ann Intern med $1994 ; 121 ; 124$

7. Couto F, Naolkami N.S, Jose M: Ovarian tumours in Goa, A clinicopathologic study J obstGynec India 43:408-412,1993.

8. Di Bonito L, Patriarca S, Delendi M, Alberico S, Ovariantumours: anatamohistopathological contribution to their interpretation, Eur J Gynaecol Oncol.1988;9(4):324-30.

9. Gershenson DM: Epithelial ovarian cancer, Textbook of gynecology, cope land LJ,1993, WB Sauder Co.

10. Gunnar Kvale,IvarHeach, SteinarNilssen.Reproductive factors and risk of ovarian cancer. International Journal of cancer 2006:42(2):246-251.

11. Gupta SC Singh PA, MchrotraT.N. A Clinicopathological study of ovarian tumours India J Path Micro 29,354-362,1986.

12. Herbst L:The epidemiology of ovarian carcinoma and the current status of tumour markers to detect disease Amjobst and gynec 170:1099-1107,1994.

13. Jemal A, Siegal R, Xu J, Ward E. Cancer statistics, 2010. CACancer J Clin 2010; 60:277.

14. Kapas MM and RalMC: Varities of ovarian neoplasm. Jobst and Gynec India 32,810$815,1987$.

15. Maheswari V, Tyagi S.P, Saxena et al: surface epithelial tumours of the ovary. Ind J Patho Microbiology 37:75-85,1994.

16. Mondal SK et al Histological pattern, Bilaterality and Clinical evaluation of 957 cases of ovarian tumours-A 10 year study in a tertiary care hospital of Eastern India, Journal of cancer Research and Therapies 2011

17. Nalinigupta, DiptiBisht, Anil Kumar Agarwal, Veena K Sharma, Retrospective and prospective study of ovarian tumours and tumour like lesions Indian J patholMicrobiol 2007:50(3):525-527.

18. National Institutes of Health Consensus Development Conference Statement. Ovarian cancer: screening, treatment, and follow-up. GynecolOncol 1994;55:S4.

19. Pilli GS, Suneetha KP, Phaded AV, Yenni VV. Ovarian tumours: a study of 282 cases J Indian Medical association 2002;423-4.

20. Ramachandran G, Harilal KR, Chinnamma KK and ThangaVelu H: Ovarian neoplasm-a study of 903 cases, JObst and Gynec India:309-315,1972.

21. Tyagi SP, Maheswari V, Tyagi N, Saxena K, Sharme R and Hamced F: Solid tumours of the ovary, JIMA;91:227-230,1993. 